\title{
An Autoethnographic Account of Experiences with a Community- Based Participatory Research Project in Canada
}

\author{
Uma Descrição Autoetnográfica de Experiências com um Projeto de
}

Pesquisa Participativa Baseada na Comunidade no Canadá

\author{
Martha Dowsley \\ Frederico Oliveira $^{1}$
}

Recebido em 29 de junho e aprovado em 10 de julho de 2018.

\begin{abstract}
We discuss our personal experiences while developing a community-based participatory research project (CBPR) with Lac Seul First Nation for the purposes of recording some of their land use history and for the training of youth from the First Nation and students from our university in Archaeology, Social-Cultural Anthropology and Geography. Drawing on Geography and Anthropology literature we illustrate how both disciplines influenced our work and understandings of our professional and personal journeys. We discovered primarily that the traditional academic research phases of project design and data collection did not adequately describe the birth of the project and the subsequent information exchange. Instead, we found that the phases of research that were important were: Relationship building, Project design, Learning, Immersion/Data Collection and Activism/Shifting Perspectives.
\end{abstract}

Keywords: Indigenous Research Methods. Traditional Teachings. Entanglement. Encounters. Anthropology. Anishinaabe Culture. Geography.

Resumo: Discutimos nesse artigo nossas experiências pessoais ao desenvolver um projeto de pesquisa participativa baseada na comunidade (CBPR) com a Primeira Nação do Lac Seul para registrar algumas de suas histórias de uso da terra e para treinar jovens da Primeira Nação e estudantes de nossa universidade em Arqueologia, Antropologia Cultural e Geografia. Com base na literatura acadêmica dos campos de Geografia e Antropologia, ilustramos como ambas as disciplinas influenciaram nosso trabalho e o entendimento de nossas jornadas profissionais e pessoais. Descobrimos principalmente que as fases tradicionais de pesquisa acadêmica do projeto e coleta de dados não descreviam adequadamente a fase inicial do projeto e a subsequente troca de informações. Em vez disso, descobrimos as seguintes fases de pesquisa que se tornaram importantes: Construção de relacionamentos, Projeto, Aprendizado, Imersão / Coleta de dados e Ativismo / Mudança de perspectivas.

Palavras-chave: Métodos de pesquisa indígena. Ensinamentos Tradicionais. Envolvimento. Encontros. Antropologia. Cultura Anishinaabe. Geografia.

\section{Key messages}

- The traditional academic research cycle of project design, data collection, data analysis and knowledge mobilization neglects key elements for research with Indigenous 
populations and therefore phases of relationship building and cross-cultural learning should be added near the beginning of the research cycle;

- Anthropology offers ideas, such as the concepts of Encounter and Entanglement, which help us to understand and act within researcher-Indigenous community relationships during Community-Based Participatory Research Projects, and can help us decolonize our methodologies;

- Combining Geography and Anthropology field research in an immersive Indigenous community setting provided a rich learning experience for university students and First Nations youth and contributed to greater understandings of historic and modern issues facing Indigenous peoples in Canada.

\section{Introdution}

Our goal is to add to this conversation by combining two very peculiar and complementary standpoints when we think about the academic background, ethnographic training and research focus of the authors of this paper. Also an interesting mix can be verified regarding the sense of peripheral and core anthropologies that guides our experience when we try to find comprehensive ways to work and describe Indigenous populations. Martha Dowsley, currently a professor at Lakehead University (Thunder Bay, Ontario) concluded her $\mathrm{PhD}$ in Human Geography at McGill University (Quebec) working with Inuit and developed her Masters research (Forestry, University of Toronto) working with the Kayapó people in Brazil. She has a consistent experience working with Inuit and currently develops research with Anishinaabe groups in Northern Ontario. Frederico Oliveira, currently a professor at Lakehead University (Thunder Bay, Ontario), completed his $\mathrm{PhD}$ at Universidade de Brasilia (Brazil), working with the Kaiabi people in Brazil and currently develops research with Anishinaabe people in Northern Ontario. Essentially, we have Dowsley (Canadian) with a diversified humanistic (although non-anthropological) experience working with indigenous peoples and Oliveira (Brazilian) with strong academic influences derived from classical schools in sociocultural anthropology, but not the type of school that is predominant in most universities in Canada, especially in Ontario. The structure of a four-field anthropology (coming from United States) that is common in many Canadian universities (including Lakehead) and the applied direction to work with Indigenous peoples came as interesting challenges and counterparts to the robust background in theory and social organization from Oliveira and the field oriented approach from Dowsley. 
We wish to share our experiences while developing a research partnership between non-Indigenous university researchers in the fields of archaeology, social-cultural anthropology and geography and an Anishinaabe (Ojibwe) First Nation (Lac Seul/ Obishikokaang). We seek to highlight some of our successes and challenges in pursuing an interdisciplinary research project using an Indigenous methodology and a mix of data collection methods from Western science and social sciences as well as Anishinaabe teachings. We feel that both Anthropology and Geography will be enriched and brought closer together through sharing our experiences.

As Canadians are called towards actions for reconciliation with Indigenous populations (TRC, 2015) and various research governance bodies have instituted improved ethical standards and procedures (Tri-Council TCPS2; First Nations Information Governance Centre's OCAP, 2014; USAI (OFIFC, 2012), there is a growing body of geographic literature emerging that examines research methods for projects involving academic researchers and Indigenous communities (MARKEY et al. 2010; GRIMWOOD et al. 2012; COOMBES et al. 2014; DRAWSON et al, 2017). We hope that the outcome will be increased self-awareness for researchers and community members during their research Encounters and a push for ourselves and our academic colleagues to further decolonize our methodologies and methods.

The process used in our project with Lac Seul fits within the framework of community-based participatory research (CBPR) (MARKEY et al. 2010; CASTLEDEN et al. 2012a; DRAWSON et al. 2017), an approach also called research co-management (HEIKKILA and FONDAHL, 2012). CBPR is widely practiced (at least in part) by academic researchers in their work with Indigenous communities (CASTLEDEN et al. 2016b). It can be defined generally as a research relationship in which researchers and communities share power, learn and share in mutually beneficial ways. Part of CBPR is to challenge conventional approaches to research, relationships and knowledge sharing (CASTLEDEN et al. 2012b; DRAWSON et al. 2017). CBPR seeks to promote equity through its tenets of respect, relevance, reciprocity and responsibility to Indigenous communities (KIRKNESS and BARNHARDT, 1991). CBPR is thus an approach to research, rather than a method and can include many 
tools for collecting, analyzing and sharing data. CBPR serves as the umbrella for our research project and learning experience.

We further understand that it is a challenging exercise to move away from the premises of the consecrated stages of the scientific method and see the process being directed by another set of guidelines that are not fully ours (as researchers), but simultaneously not fully those of our Indigenous partners. Rather, the process is a set of guidelines and values that arise from interaction, which can be understood using the anthropological concept of the Encounter. Situating ourselves in this viewpoint, we aim to recognize the 'Otherness of the Other' or the 'Other as face' in the relationship (LEVINÁS, 1969; ASCH, 2001). A philosophy based on ethics demands that there are always two parties, a Self and an Other that cannot be reduced, or integrated, as a single unified theoretical perspective, methodological approach, or sense of outcome. This is the essence of the challenge when knowledge based on Western scientific premises deals with other forms of being and knowing. Awareness of this challenge is a good way to begin CBPR, but it does not mean we were immediately able to get rid of the tendency to reduce the Other to the Self in our project. We noticed however that our First Nations partners seem to operate quite naturally with these notions of sharing and a genuine respect for us as their Other in the relationship. Maintaining this recognition of the Other and of the Encounter as neither fully directed by either us or the Other, but rather as a mutual construct, was a frequent discussion point amongst ourselves and with our Anishinaabe interlocutors throughout the project.

The specific nature of our project, to examine aspects of the relationship between Anishinaabe and their traditional lands, also brings to mind the notion of Entanglement (DUSSART AND POIRIER, 2017). The last few centuries of Anishinaabe history have become increasingly entwined with the history of settlers. Our project does not specifically focus on forms of resistance, colonialism or other structured forms of analysis. Instead, we find that it fits within the conceptual framework of Entanglement, which focuses on what is happening in all the relationships through time without privileging one process, operator, object or representation. As different cultural groups come into contact, in this case through the milieu of a colonial history, they become irreversibly connected in a 
dialogical relationship of Entanglement. In that sense, Entanglement is more than the sum of its parts. It involves all aspects of the Self and the Other and their effects on each other. Once Entangled, the involved systems cannot be described independently and the outcomes of any Encounters often cannot be predicted (DUSSART AND POIRIER, 2017). Using this concept, we can better acknowledge the long and complex history of interactions between settler, Anishinaabe and other systems that are also Entangled with these, which may include other political and cultural groups, as well as non-human actors. In the case of Lac Seul, a key moment in their Entanglement with the non-Indigenous Canadian society was the creation of a hydro-electric dam in 1929 which dramatically and tragically affected their economic, social and cultural livelihoods. They have been dealing with the outcomes of that event for nearly 100 years and it continues to influence many aspects of their lives today.

Our task here is to describe some of what was encompassed by the experience we had in developing a CBPR relationship with Lac Seul First Nation, both as group and personal Encounters. We also recognize that our two groups of actors were already Entangled at a societal level and became much more so at a personal level through the CPBR project. This report on our research project is structured somewhat differently from the conventional organization of the phases of the research cycle (project design, data collection, data analysis and knowledge mobilization (CASTLEDEN et al. 2012b), as we feel these do not adequately highlight the phases of research with Indigenous communities. Instead, we find that Grimwood et al.'s (2012) idea of 'engaged acclimatization' is useful to express our personal journey as non-Indigenous people doing research with an Indigenous community as we moved through Grimwood et al.'s four phases of learning (relationship building, learning, immersion and activism). We have structured our report by combining the phases of engaged acclimatization with the first two phases of the conventional research cycle to explore our experiences during the first part of the CBPR project. This paper is thus divided into sections on relationship building, project design, learning, immersion/data collection, and activism (in which we include shifting perspectives). The later phases of the CBPR project will be explored in forthcoming papers. In keeping with the interdisciplinary nature of the project and Anishinaabe storytelling and sharing 
traditions, we have chosen to report our experiences in an auto ethnographic style coming from anthropology (WALL, 2006; SMITHERS GRAEME, 2013). The goal in using this technique is to share our personal experiences and lessons by speaking from the heart. It is not our objective to speak for our Anishinaabe partners.

\section{Relationship Building}

The relationship building process between Lakehead University and Lac Seul First Nation started casually with the parties getting to know each other and discussing the best possible ways to work together. Initial contact was made in 2013 with the mediation of a Master's student at Lakehead who was also a Lac Seul member and was proposing his own separate research project involving the community. Oliveira was invited by the Chief and Council to visit Lac Seul and discuss potential collaborations and partnerships. A couple of formal meetings took place in Lac Seul where Oliveira had a chance to present his academic background working with indigenous peoples and his experience on the topics of ecological anthropology, aboriginal rights and land use and occupancy studies. In addition, a number of other informal conversations occurred when the Chief or Council members were able to visit the second author in Thunder Bay or talk by telephone. The main purpose of these initial meetings was for Lac Seul members to familiarize themselves with his research focus and present ideas and priorities that would be related to his background. Preliminary assessments showed that it would be useful for the community to co-design a CBPR project in order to gain a better understanding of the history of human occupation and use of their traditional lands and thus to tell the story of Lac Seul.

Based on this initial direction, Oliveira invited professors Dowsley (Geography/ Anthropology) and Hamilton (Archaeology/Ethnohistory) to join the process of relationship building, adding their complementary expertise and to work as a team to apply for internal university seed grants. These grants proved very important in nurturing the relationship with Lac Seul without having to impose any narrow research agenda on Lac Seul, which might have compromised the nascent partnership. Essentially, Oliveira spent the summers of 2014 and 2015 in direct contact with Lac Seul, talking to the Elders 
and knowledge holders, and familiarizing himself with the socio-political organization and the life style in the community. This slow beginning to the research partnership allowed the two partners to engage in multiple informal interactions and co-create the social guidelines and expectations of the more formal Encounter of the CBPR.

During the summer of 2015, Oliveira came to an agreement with the Chief and Council that a research proposal would be submitted to the Canadian Federal Social Sciences and Humanities Research Council (SSHRC) Insight Development Grant program for a two-year project focusing on two interconnected objectives: 1. the establishment of a field school in archaeology and ethnography to train Lakehead University students and Lac Seul youth in theories and methodologies from both disciplines and 2. the development of a series of cognitive/biographical maps of land use and occupancy, following the priorities expressed by Lac Seul to achieve a deeper and historical understanding of the current and past uses of their traditional territories. At the time of the development of the grant, we came to understand that there were other groups within the community whose approval for the project was necessary in order that the relationship could be built on a more solid foundation. There is, for example, the KichiPaawitik River Park Working Group that is responsible for mediating relationships and agreements with external partners. For our project, Lac Seul nominated a member from the KichiPaawitik River Park Working Group to be in constant contact with the academics from Lakehead and to act as an indigenous liaison and advisor to keep the community apprised of progress on the project, to coordinate internal community discussions and relay the outcomes of these discussions to the university partners.

After we received the SSHRC grant in the spring of 2016, we applied for ethics approval from the university Research Ethics Board (REB). Our first challenge in this endeavour was recognizing that the research ethics outlined by the tri-council and our university to work with "human subjects" is not the same set of ethical guidelines we were trying to abide by in our Encounter with Lac Seul, which is guided by a decolonizing/ participatory/indigenous perspective. The imposition of conflicting definitions of ethics caused difficulties for the implementation of the relationship as we had initially agreed between our academic research group and Lac Seul First Nation. The first challenge arose 
in trying to convince the university's Research Ethics Board (REB) that research could still be respectful if our application for the REB approval was not able to accurately forecast the number of participants, the questions that would be asked, where interviews would take place as well as a number of other questions that are supposed to provide a measure of security to the REB that research participants are not harmed. We argued to the REB that due to the spontaneous formats of the interviews and the very qualitative nature of the research, it was not possible to respond exactly to some of the items requested by the REB reviewers. We explained that we would rather be honest, honouring the principles of our academic disciplines and the relationship we were building with Lac Seul, than to provide answers that would not reflect the real situation in the field. A second concern raised by a REB reviewer was that considering the high level of community engagement required by the research, an agreement establishing the roles of the research team and the protocols for knowledge dissemination should be signed before any participant would be addressed and before the research could get started. We replied stating that such an agreement was supposed to be discussed and signed with the community, but for this to happen we needed the clearance from the REB to access our funding to visit Lac Seul, discuss the terms with our partners, give them some time to discuss it internally, have it returned to us and eventually have it signed. After all the time and challenges we had overcome in our initial encounters with Lac Seul to establish the preliminary relationship, receive the approval of the community, and then apply for and win a very competitive grant, we saw ourselves facing the possibility of our project being interrupted because we were unable to honestly follow the university REB ethics protocols. Our main concern when dialoguing with the REB was to respect their good intentions to protect research participants, but to offer our alternative perspective which caused us to be non-compliant with the rules. We requested their allowance of a more holistic and flexible approach to develop research with indigenous peoples. After a series of conversations with the REB's chair, we received the clearance to move forward with the research and permission to visit Lac Seul to work on the research agreement, and to add further details to our ethics application at a later date. 
We had already discussed the creation of a research agreement with Lac Seul, our next step was to complete and sign it with them. The idea was to formalize the partnership and recognize the right of Lac Seul to manage information about their people as an element of self-determination and to preserve their culture. Essentially, the agreement sought to emphasize that the process of knowledge acquisition and circulation would respect both languages and modes of knowledge and find a common path. The agreement would not forbid Lakehead's researchers to publish academic papers using the results of the research and neither did it have any kind of oppositional or legally binding structure. It was designed mainly to work as a symbol of the cooperative and reciprocal relationship that was being established between Lakehead University and Lac Seul.

All of these philosophical, ethical, academic, geographic and temporal challenges in the early phases of the project really highlighted for us that CBPR does not start with the conventional first phase of research: project design. The pre-design work lasted several years as the university and community members informally negotiated the framework of the Encounter and new challenges seemed to appear with each step we made towards formalizing a project. We became aware of the Entanglements we are party to as university researchers, bound by the formal ethics procedures of the university and the Tri-council, and saw how these rules, which have come out of the spirit of reconciliation and rectifying past wrongs on the part of researchers, did not exactly fit with our qualitative, ethnographic field methods. However, the challenges also provided lessons for us and allowed us to have mutually educational discussions with our Research Ethics Board, our First Nations partners and each other about how to proceed in ways that were true to our intentions and would set a positive precedent for future endeavours.

\section{Project Design}

Our research intention was to collect data for the community (see KOSTER et al. 2012) that we could also use to publish academic papers, teach undergraduate students and First Nations youth and provide opportunities for graduate students to develop theses. With Lac Seul, we decided to combine teaching methods from Anishinaabe traditional teaching, geography, archaeology and social-cultural anthropology in order to meet the stated 
intentions. More specifically, on the academic side we decided to employ social-cultural anthropology research methods of ethnography, participant observation and semi-directed interviews, archaeology methods of site reconnaissance and shovel testing, and geography methods of GIS mapping and map biography interviews in an interdisciplinary approach to recording and mapping historic and contemporary land use. On the Anishinaabe side, an Elder in Residence joined our field school, and we worked closely with an Anishinaabe educator who served as a Visiting Teacher, as well as other Anishinaabe Elders and colleagues throughout the project. These teachers helped us gain a greater understanding of how to develop culturally appropriate relationships of respect and reciprocity as they shared knowledge on traditional Anishinaabe cultural practices and spirituality which provided us with context, an interpretive perspective and personal lessons.

We held a two-week field school during the data collection phase of the project to bring university students and community youth into the project and to partially meet the objectives. The university students used the experience as part of a one-semester undergraduate anthropology credit while the community youth logged their hours as part of high school volunteering/work experience credits. Our group goal in the field school was to gather historic occupancy data, to provide training in research methods, to provide opportunities for cultural exchange between the university and First Nations students and to provide a space for our Anishinaabe teachers and Elders to teach the students and non-Indigenous researchers about Anishinaabe culture in an immersive setting. We hoped that this style of learning would be a transformative experience for the undergraduate students as field schools focusing on Indigenous topics have been for others (CASTLEDEN et al. 2013).

\section{Learning}

One of the first teachings we received was how to introduce ourselves to community members. We had been describing our role using the term 'researcher' as opposed to professor or other terms we had found to be intimidating in our experiences with other Indigenous communities. However, we were soon educated that 'researcher' here was steeped in connotations of colonial research methods and would not encourage 
a collaborative or trusting relationship. Others have made the same comment (SMITH, 1999). This lesson, combined with equal concern for some other labels that other communities have raised with us in the past, has taught us to ask how to introduce ourselves around the community.

During the few days we spent in Lac Seul to initiate the research grant in the summer of 2016 and discuss the terms of the agreement, we were invited to a pow wow and were introduced to a number of examples of how Lac Seul people were finding strategies to revitalize their culture and their identity since the flooding and on-going colonial relationship with the Canadian government. The pow wow offered us opportunities to learn and to introduce ourselves both through our words in private conversations, but also in our actions of trying to learn, be helpful and to dance. The decision to present ourselves to the community through participation in the pow wow was not necessarily without repercussions, for example, the pow wow included traditional spirituality. Its revival a few decades ago was not championed by the whole community. Other factions following different religious perspectives may not have viewed our actions in the same light as those who invited us. We have not been told this, but there is an undercurrent of distinct religious identities within the community. Our decision was both a response to a friendly invitation and part of our goal as anthropologists to show respect and appreciation for other cultures and our intention in this decision and others was to become students of Anishinaabe culture. Recognizing diversity within Indigenous communities and handling relationships with individuals from different religious and political groups within an Indigenous community is an important consideration and potential challenge for outside researchers that we wish to highlight.

Personal relationships we nurtured during that summer visit continued through the winter with phone conversations and visits with friends from the community as well as meetings with Chief and Council when they visited Thunder Bay. During the winter, D. also took an Ojibwe language course at the local Indian Friendship Centre (since renamed Indigenous Friendship Centre). This is encouraged preparation for fieldwork in Anthropology, but we have not seen mention of it in our review of the Geography literature. Having some basic language skills proved very helpful both in personal 
interactions throughout the project and in comprehending maps and ceremonies during the immersion/data collection phase of the project. Further, participating in the Friendship Centre in Thunder Bay also taught us more about concerns of Anishinaabe and nonIndigenous allies in Northwestern Ontario, and especially Thunder Bay, where a string of suspicious deaths of young Indigenous people have occurred (CBC, 2016), and where combating racism and other social issues is a priority. Interacting with the Anishinaabe community in Thunder Bay through this formal learning process, as well as our informal interactions also highlighted the multitude of ways in which the settler and Indigenous experiences are Entangled.

In early spring 2017 we returned to Lac Seul to prepare for the field school. We conducted some archaeological inspection activities to consider options for that portion of the field school and refreshed our relationships with community leaders and Elders. We were directed to visit the shores of the lake at this time because the water levels are low in the spring and subsequently rise as the dam is closed for the summer. Water levels range over 3 meters annually and are a key feature of the post-dam ecology of the area. This highly visual and significant reminder of government unilateral decision making colours many relationships for Lac Seul people within both their tradition circle of interactions with each other and the non-human world and within their Entanglement with the settlers.

During the spring visit Oliveira and Dowsley were invited to participate in a sweat lodge, although initially we thought the invitation was to a meeting to discuss the project. Our humorous mistake taught us to pay better attention to how information is communicated by Elders, a lesson we continued to learn throughout the project. The sweat lodge ceremony itself taught us about traditional Anishinaabe spirituality through symbolism, music and physical experiences and thus laid the foundation for us to become better students of traditional Anishinaabe culture. Through this experience and others, we also began to perceive the importance of self-reflection, sharing and mutual support as a frequent orientation for interacting with our hosts. We observed this orientation towards the Encounter with both Anishinaabe who followed traditional spiritual practices and those who followed other religious traditions. Our recognition of the importance of seeing the Other as a face came up here as well. This very personal method of interaction blurred 
the line that is often drawn in Canadian settler society between one's professional and personal lives. It became important for fruitful social interactions to follow Anishinaabe social protocol and we began to practice expressing ourselves in this way. This style of interaction was critical to the Encounter because it nurtured a relationship that was broader than the research partnership and helped to create social capital which in turn also helped the research relationship.

\section{Immersion/Data Collection and Field School}

We decided to stay on the First Nation reserve for the two week field trip and to blend the academic and cultural activities to create a more holistic experience. Oliveira, Dowsley and a Research Assistant arrived in the community a few days before the students and archaeologists. We visited our contacts and friends, and one Elder volunteered to serve as an Elder in Residence and stay with us at the house we rented. Another respected Anishinaabe activist also joined us at the house for several days as a Visiting Teacher. As the field school unfolded these two women shared many teachings with us and were an invaluable addition to the learning experience for both the students and professors. The first morning of the field school a high school resource teacher arrived with four students who joined us daily for the next two weeks. We settled into an approximate routine whereby each day Oliveira, Dowsley and Hamilton divided up the university and high school students and each team collected data through either interviewing and creating maps with knowledge holders in the community or participating in archaeological reconnaissance or digging test pits to establish physical evidence of occupancy. The dynamic of the data collection was organized so that interviewees would be recounting their memories with the land and feeding the archaeological approach to physically contextualize their stories. The undergraduate students were also assigned to transcribe interviews and spent much of their unscheduled time with the First Nation youth either participating in community sports or 'hanging out'. During the evenings the students would share their experiences with the whole group so that everyone could be updated regarding the activities of the three teams. 
The field school offered many opportunities for informal cultural learning for the Lakehead University contingent. Students were able to observe the challenges of interviewing cross-culturally and the patience required to complete the interviews, maps and transcriptions. They began to grasp the 'deep hanging out' (GEERTZ, 1998) of social-cultural anthropology through conducting participant observation. This was exemplified by the frequent unscheduled occurrences of facets of daily life for our hosts including catching and cleaning fish, butchering moose meat, family barbeques, late-night interviews, shopping and moving around the large reserve and associated land and water. All of these experiences complemented the 'formal' learning about how the First Nation relates to their landscape and how research with human subjects should be conducted in an Indigenous context. The flexibility necessary in scheduling to take advantage of these opportunities was also a lesson in how to organize and conduct research as a conversation with the community. Serendipitous events (GRIMWOOD et al. 2012) or experiencing the imponderabilia of actual life (MALINOWSKI, 1932) are often where the most profound learning occurs and our residency on the reserve facilitated these.

The field school also provided us with more structured teachings on Anishinaabe culture. Our Elder in Residence interacted individually with each group member, providing teachings and serving as a guide and model for appropriate behaviour. She also trained us in ceremony, for example in how to make tobacco ties that are offered to traditional Elders when making a request. Our Visiting Teacher conducted a teaching circle presenting the knowledge of the Medicine Wheel. We also participated in sharing circles, smudging and drumming. Our cultural immersion culminated in a sweat lodge where some of the students were able to physically enact or 'embody' what they had learned about Anishinaabe culture. Embodiment is an Anthropology idea considered a significant means to understanding ritual and culture (MASON, 2010). Through their participation, the students learned how to conduct themselves appropriately and had the opportunity to practice opening themselves spiritually and emotionally in keeping with the style of relationship interaction we had been learning.

As the leaders of the Lakehead university group, we, Oliveira, Dowsley and Hamilton were also instructed in some more nuanced cultural matters. These included 
the deeper connection to the landscape that is expressed through Anishinaabe spirituality. We received teachings regarding how humans and other living things interact and communicate and the importance of dreaming, fasting, smoking pipes, drumming and the sweat lodge in opening these lines of communication. Learning Anishinaabe teachings in the setting of the reserve rather than a formal workshop or other more western learning situation helped us to better understand the data and the repercussions of the historical transformations that have occurred for this community. Furthermore they assisted us in developing an interpretive approach to the data that was more closely allied to an Anishinaabe perspective (although we do not claim to be knowledge holders and rely on our partners to guide the interpretation of the data as the project moves forward).

The conversational approach we used for the research project and tried to encourage in our interviews was very helpful in developing relationships and in gathering data. We would like to report an example that illustrates the challenges and rewards of the approach. During an initial interaction before an interview was scheduled, Oliveira was asking permission from an Elder to engage in a map biography interview with him. The Elder changed the conversation to discuss how anthropology has a long history of appropriating voices. He mentioned how unimportant he felt a number of times when significant decisions about the future of his community were being discussed in a language he could not understand between anthropologists and lawyers, especially during the interactions with "experts" for the flooding lawsuit process. Then he gently said he would prefer not to participate in our study. To deal with this type of situation, we learned to self-reflect about the colonizing history of academic discipline with our interlocutors, but also put ourselves in a position to trust our approach and make an effort to change common categorizations of university or government researchers. Oliveira continued the conversation, learning more details of the Elder's concerns and in return explained the process of relationship building and the participatory aspect of the research with Lac Seul. In the end, the Elder agreed to participate and became quite engaged in relating his life experiences with the land and provided one of the most detailed and profound map biographies. The hesitant attitude before the interviews is justifiable and happened on several other occasions with participants asking questions about the purpose of the 
research, if the Chief and Council have approved it and what were the expected outcomes of the project before they would allow us to discuss the details of the project or review our university ethics forms and ask for them to sign a permission form. In all of these cases, people received appropriate answers to their questions and were always given the opportunity to withdraw from the study. Fortunately, all of them decided to give their contribution and it was common and rewarding to see the changing of attitude as the interview progressed and people felt that their stories with the land were being recorded and validated for a purpose that would benefit their own community.

\section{Activism/Shifting Perspectives}

One of the tenets of CBPR is activism (COOMBES et al. 2014) and Grimwood et al. (2012) see it as an effect of engaged acclimatization. Certainly the community's research goal of recording more data on their historic and current land use clearly had an activism goal of struggling against the colonial history that has denied them access to their resources. We also began to shift our perspectives as outsiders into more activist stances as we learned about Indigenous resistance and activism. Plenty of evidence of colonialism was experienced during our field school, which helped combat the geographies of ignorance common to settlers (see CASTLEDEN et al. 2013). Physical and map evidence illustrated ways in which Lac Seul lost land and resources due to government management, and unilateral imposition of industrial natural resource development (i.e. hydro-electric development, forestry) to the detriment of local Indigenous residents. Oral history of shifts in resource use, increasing loss of resources, residential school trauma and racism all emphasized these issues for the visitors. But we also witnessed adaptation and resilience, for example in the attempts of a few generations past to reseed wild rice beds after hydro-electric flooding caused by a dam and how people are currently reconnecting to their traditional trapping grounds. The work of contemporary local activists in cultural revival was also a major theme of our experience. The re-introduction of the pow wow, learning how people take on the responsibility of becoming traditional Carriers of ceremonies and sacred objects and discussions of how traditional spirituality was helping some people deal with psychological traumas were key learning moments 
for our group. As Grimwood et al (2012:225) emphasize, bearing witness to the resilience of Indigenous groups shifts the focus from negative narratives to "positive possibilities and capacities". For Dowsley one moment where our choice to take on a stronger activist stance was underscored when our Visiting Teacher invited her to participate in an activist photo project for Canada 150 (the country's $150^{\text {th }}$ anniversary of confederation) focusing on Indigenous issues. Problems with the colonial meta-narrative of First Nations people in our country and region will continue to surface and provide us with opportunities for learning and engagement.

As we move into the data analysis and knowledge mobilization phases of the research we are working with Lac Seul to craft products for their purposes. We are well aware of the professional and institutional challenges that academic researchers often face in trying to use a participatory approach to these phases (CASTLEDEN et al. 2012a; b; COOMBES et al. 2014). Because we would like to continue our partnership with Lac Seul into the future on other projects, we are not concerned with time as a potential barrier to developing knowledge mobilization products, and we are committed to exploring nontraditional venues for sharing in order to reach non-academic audiences, especially Lac Seul band members. Our first product is a brief video about the field school, available on Youtube (https://www.youtube.com/watch?v=bUApdaWf2Gc) that we intend to distribute to potential funders of future field schools and other potential partners and students. Our next product will be a formal written and verbal report to the community and discussion with Chief and Council regarding knowledge mobilization projects. All the map biographies, audio recordings of the interviews and artifacts collected are expected to be stored at the Lac Seul Cultural Centre, and the analysis of these data will likely be finished in the next couple of years. We are also discussing designing another field school involving local youth creating their own dissemination products potentially using music, radio shows or visual media such a photo-voice or documentary videos.

\section{Lessons/Discussion}

Our engagement with CBPR through this project has provided us with many lessons. The first set, and perhaps the most important was about our own culture as non- 
Indigenous academics in a Canadian university. Our ethical intentions with the project were broadly the same as the intentions of the Tri-council and university ethics policies, but we struggled to frame our project in appropriate ways to meet the specific guidelines for gaining university ethics board approval. Thanks to progressive colleagues on the Research Ethics Board, we were able to negotiate an acceptable path through this fraught, but important, process. University ethics criteria follow federal guidelines, both of which are oriented to more quantitative social sciences where formal surveys or interviews are used to gather data in a clinical setting. They are not currently very accommodating of a more qualitative, informal ethnographic data collection style.

The second set of lessons related to interaction with our Anishinaabe partners. These include a plethora of social interaction lessons such as locally-appropriate terminology for introducing ourselves in the project, recognition of knowledge holders and how to respectfully interact with them, cultural frameworks for facilitating trust and friendship through sharing and mutual support, acknowledging and navigating First Nations community diversity, and culturally specific non-verbal communications. Our corporeal experiences taught us new ways of being and working and provided us with emotional and spiritual lessons. We are sure these are not all the lessons we were meant to learn, but hope that we will continue to receive such teachings.

While this was an interdisciplinary project and we consciously avoided dividing our work into specific disciplines, in reviewing the Indigenous methods literature in geography for this paper we were struck by the lack of prevalence of some knowledge and practices that are common in social-cultural anthropology. We highlight three of them here. The first is the need to accept that the role of the researcher is really that of a student of culture. This entails being willing to make mistakes, feel uncomfortable and laugh at oneself (ex. SMITHERS GRAEME, 2013). By accepting this social position researchers may better progress towards equity with their interlocutors and begin to learn and thus conduct their research in a meaningful way. The second and easily remedied lesson is the value of learning basic skills in the local language of the partner community. While most of our work and learning was conducted in English, knowing how to greet and thank people allowed us to express our respect and willingness to learn. More advanced basic language 
skills were extremely helpful in understanding place names and understanding the flow of ceremonies. It was also useful for following the gist of conversations between a translator and unilingual interview participant and thus asking on-topic follow up questions. Our third observation from anthropology and an important lesson for our undergraduate students was the ethnographer's understanding of the need for two phases of timebased behaviour during data collection or immersion phase. Informally called 'hurry-up and wait', social-cultural anthropologists, in trying to take advantage of serendipitous opportunities for cultural learning, seem to always be in one phase or the other. On the one hand, it is critical for ethnographers and other qualitative researchers to be ready to seize opportunities for cultural learning. On the other hand there are lots of schedule cancellations, downtime and moments when one feels a bit lost about how to find another learning/data collecting opportunity. It is advisable to use the 'wait' phase to prepare for the 'hurry-up' phase. Activities that promote further learning need to be prioritized, such as ensuring gear and provisions are ready to go. Once these are completed the down time needs to be used to catch up on transcriptions, downloading data or other 'research' work. Researchers in both the sciences and the social sciences can benefit from using this frame of mind because accidental meetings or events often provide new data and perspectives on the larger research program. We therefore encourage other researchers to adopt the traditional Anishinaabe perspective to look at every delay, cancellation, and change in plans as being a sign that something else important will happen.

Finally, this CBPR project provided us with lessons of use to our personal and professional lives. For example, Dowsley received counsel on how to cope with the weight of emotional personal histories shared during interviews that touched on such topics as residential school abuses and personal tragedies. Discussing and understanding the emotional work that comes from conducting interviews and working with marginalized populations is often de-emphasized in academia, but is an issue for many social science researchers. Academics may receive some advice on this issue as a $\mathrm{Ph}$.D. student from a supervisor, but it is rarely discussed openly among our colleagues. We hope mentioning this will bring it into the broader conversation. 


\section{Conclusions}

The challenges and positive experiences we had during the first phases of the traditional research cycle and through Grimwood et al.'s (2012) engaged acclimatization framework helped us develop our participation in the CBPR project. We find that our experiences are specific, but fit into the patterns of other researchers (CASTLEDEN et al. 2012a; b). We thus urge others to consider combining Grimwood et al.'s research phases with those of the conventional research cycle to more heavily emphasize the participatory aspects of CBPR.

For us, living only a few hundred kilometers from our research site, and interacting with Anishinaabe in our city regularly, the Encounter of the research project links us to a much larger Encounter occurring every day in our city and more generally, but perhaps often less easily observed across Canada as we look for ways to move towards Reconciliation. We are not able to leave the field as easily as colleagues working in locations more distant socially and physically from their homes, nor do we particularly want to. The lives of settlers like ourselves and Indigenous people are very much entangled and our positions as social science researchers affords us opportunities to engage with and improve that entanglement in myriad ways.

\section{References}

ASCH, M. Indigenous Self-Determination and Applied Anthropology in Canada: Finding a Place to Stand. Anthropologica 43(2): 201-207. 2001.

CASTLEDEN, H., K. Daley, V. Sloan Morgan and P. Sylvestre. Settlers unsettled: Using field schools and digital stories to transform geographies of ignorance about Indigenous people in Canada. Journal of Geography in Higher Education 37(4): 487-499. 2013.

CASTLEDEN, H., M. Mulrennan, and A. Godlewska. Community-based participatory research involving Indigenous peoples in Canadian geography: Progress? An editorial introduction. The Canadian Geographer 56(2):155-159. 2012a.

CASTLEDEN, H., V. Sloan Morgan, and C. Lamb. "I spent the first year drinking tea": Exploring Canadian university researchers' perspectives on community-based participatory research involving Indigenous peoples. The Canadian Geographer 56(2): 160-179. 2012b. 
CBC. First Nations student deaths inquest: 5 recommendations we've heard before. On line: http://www.cbc.ca/news/canada/thunder-bay/selena-sakanee-inquest-repeat-1.3660371. 2016 July 1 st.

COOMBES, B., J.T. Johnson, and R. Howitt. Indigenous geographers III: Methodological innovation and the unsettling of participatory research. Progress in Human Geography 38(6): 845-854. 2014.

DRAWSON, A.S., E. Toombs, and C.J. Mushquash. Indigenous research methods: a systematic review. The International Indigenous Policy Journal 8(2): Article 5, 25 pp. 2017.

DUSSART, F. and S. POIRIER eds. Entangled territorialities: Negotiating Indigenous Lands in Australia and Canada. University of Toronto Press. 2017.

The First Nations Information Governance Centre (FNIGC). Ownership, Control, Access and Possession (OCAP): The path to First Nations information governance. Retrieved from http://fnigc.ca/sites/default/files/docs/ocap_path_to_fn_information_governance_ en_final.pdf

GEERTZ, Clifford. 1998. "Deep Hanging Out.” New York Review of Books 45(16): 6972, 22 October. 2014.

GRIMWOOD, B.S.R., N.C. Doubleday, G.J. Ljubicic, S. Donaldson and S. Blangy. Engaged acclimatization: Towards responsible community-based participatory research in Nunavut. The Canadian Geographer 56(2): 211-230. 2012.

HEIKKILA, K. and G. FONDAHL. Co-managed research: non-Indigenous thoughts on an Indigenous toponymy project in northern British Columbia. Journal of Cultural Geography 29(1): 61-86. 2012.

KIRKNESS, V. J., and R. BARNHARDT. First Nations and higher education: The Four R's-respect, relevance, reciprocity, responsibility. Journal of American Indian Education 30(3): 1-15. 1991.

KOSTER, R., K. Baccar, and R.H. Lemelin. Moving from research ON, to research WITH and FOR Indigenous communities: a critical reflection on community-based participatory research. Canadian Geographer 56(2): 195-210. 2012.

LEVINÁS, E. Totality and Infinity: An Essay on Exteriority. Dordrecht: Duquesne. 1969.

MALINOWSKI, B. Argonauts of the Western Pacific. London: George Routledge and Sons Ltd. 1932.

MARKEY, S., G. Halseth and D. Mason. Capacity, scale and place: Pragmatic lessons for doing community-based research in the rural setting. The Canadian Geographer 54(2): 158-176. 2010.

MASON, M.A. "I bow my head to the ground": creating bodily experience through initiation. Magic Witchcraft and Religion: A Reader in the Anthropology of Religion. Eighth Edition. Moro, P.A. and J.E. Myers, eds. Ch. 13. 97-107. 2010. 
OFIFC (Ontario Federation of Indian Friendship Centres). USAI Research Framework. 2012.

SMITH, L.T. Decolonizing Methodologies: Research and Indigenous Peoples (Second edition). London: Zed Books. 1999.

SMITHERS GRAEME, C. Indigenous health research and the non-Indigenous researcher: a proposed framework for the autoethnographic methodological approach. Pimatisiwin: A Journal of Aboriginal and Indigenous Community Health 11(3):513-520. 2013.

Truth and Reconciliation Commission of Canada. Truth and Reconciliation Commission of Canada: Calls to Action. Winnipeg, MB. 2015.

WALL, S. 2006. An autoethnography on learning about autoethnography. International Journal of Qualitative Methods. 5(2): 146-160. 2006.

\section{Notes}

${ }^{1}$ Martha Dowsley is Associate Professor of Anthropology/Geography at Lakehead University, Thunder Bay, Canada (mdowsley@lakeheadu.ca). Frederico Oliveira is Associate Professor of Anthropology at Lakehead University, Thunder Bay, Canada (foliveir@lakeheadu.ca). Both authors contributed equally in the elaboration of the manuscript. 